\title{
Part-list cuing in speeded recognition and free recall
}

\author{
KARL M. OSWALD \\ California State University, Fresno, California \\ MATT SERRA \\ Duke University, Durham, North Carolina \\ and \\ ANAND KRISHNA \\ University of Maryland University College, College Park, Maryland
}

\begin{abstract}
The primary question was whether part-list cuing decrements would occur in a speeded yes/no recognition task and free recall. After studying category exemplars, participants were tested either after re-presentation of a subset of the exemplars (cues) or without re-presentation. Free recall of all study items followed the recognition task in each trial. Across two experiments, results demonstrated partlist cuing impairment in two ways: significant slowing of target recognition and lower free recall of target items in cued than in uncued trials. These findings extend the limited research on part-list cuing in recognition and support retrieval inhibition and retrieval competition interpretations of the phenomenon. Moreover, despite arguments for the necessity of the presence of cues for part-list inhibition, the present experiments demonstrate that the negative effects of cues can persist in their absence.
\end{abstract}

On the basis of the assumption that words studied together are associated (see J. R. Anderson \& Bower, 1973), presentation of a subset of study items at recall should facilitate recall of the remaining items. However, Slamecka $(1968,1969)$ has demonstrated that facilitation is not always the case; in fact, he found evidence that part-list cues impaired access to remaining items, relative to free recall of the same items. This finding of a part-list cuing impairment has since been replicated in an array of different encoding, cue, and retrieval conditions (see Nickerson, 1984 , for a review). We further explored this phenomenon by introducing a unique methodology that allowed direct comparisons between common explanations of part-list cuing effects.

There are a variety of interpretations of part-list cuing (see Nickerson, 1984; Roediger \& Neely, 1982), including strategy disruption (D. R. Basden \& B. H. Basden, 1995; Reysen \& Nairne, 2002), retrieval competition (Kimball \& Bjork, 2002; Rundus, 1973), retrieval inhibition (M. C.

We thank a host of undergraduate assistants on this project, including the invaluable help from S. Horton and A. Wiechmann. We also thank M. C. Anderson, K.-H. Bäuml, A. M. Glenberg, R. Levine, C. M. MacLeod, P. Price, M. Reysen, J. Wixted, and one anonymous reviewer for their insightful comments on earlier drafts of the manuscript. Correspondence concerning this article should be addressed to K. M. Oswald, Department of Psychology, California State University, 2576 E. San Ramon, M/S ST11, Fresno, CA 93740-8039 (e-mail: koswald@csufresno.edu).

Note-This article was accepted by the previous editorial team, when Colin M. MacLeod was Editor.
Anderson, R. A. Bjork, \& E. L. Bjork, 1994; Bäuml \& Aslan, 2004), and associative sampling bias, which is based on the quantitative search of associative memory model (Raaijmakers \& Phaf, 1999; Raaijmakers \& Shiffrin, 1981). Because of the complexity of this model and the difficulty in making novel predictions (see Roediger $\&$ Neely, 1982), the sampling bias interpretation will not be discussed further.

The strategy disruption hypothesis posits that cuing with a random subset of list items may disrupt a more efficient retrieval strategy that otherwise would have been used (D. R. Basden \& B. H. Basden, 1995; D. R. Basden, B. H. Basden, \& Galloway, 1977). Under retrieval competition, presentation of part-list cues strengthens access to those items. At recall, the probability of retrieving re-presented items is higher than that of retrieving studied noncue items (Kimball \& Bjork, 2002; Rundus, 1973). Finally, the retrieval inhibition hypothesis posits that covert cue retrieval suppresses activation to related items, as has been found with retrieval-induced forgetting (M. C. Anderson, E. L. Bjork, \& R. A. Bjork, 2000; M. C. Anderson et al., 1994). (See Bäuml, 2002, and Bäuml \& Aslan, 2004, for comparative analyses of part-list cuing and retrieval-induced forgetting.)

According to retrieval competition, part-list cuing inhibition is due to output interference (i.e., the deleterious effect of retrieving information on the subsequent retrieval of other information; see Smith, 1971) from the strengthening of the accessibility of cues, relative to noncues (Roediger, 1974). However, there is a growing body of evidence demonstrating that strengthening can- 
not solely account for part-set cuing inhibition (Bäuml \& Aslan, 2004; Bäuml \& Kuhbandner, 2003; Mueller \& Watkins, 1977, Experiment 1; Roediger, 1978) and that retrieval inhibition might provide a better explanation of part-list cuing (Bäuml \& Aslan, 2004).

To test the retrieval inhibition hypothesis, Bäuml and Aslan (2004) controlled output order after part-list relearning, cuing, or retrieving. They found a recall decrement with part-list cuing and retrieving but no decrement after part-list relearning. Because output order was controlled, these results could not be interpreted as an effect of output interference. Instead, their findings were interpreted with an instructed retrieval inhibition hypothesis: The instruction in both the part-list cuing and the retrieval conditions encouraged covert retrieval of the part-list items, thereby causing retrieval inhibition (Bäuml \& Aslan, 2004).

\section{Weaknesses and Challenges in the Literature}

Despite the ongoing research, there are a variety of findings in the part-list cuing literature that remain equivocal or relatively unexplored: eliminating the inherent confound of cuing with test, part-list effects on recognition and reaction time (RT), effects of controlling output order, and the necessity of cue presence during test. We will address each in turn.

In standard part-list cuing procedures, cues become more accessible via their presentation and are used as search probes for the remaining items. The inherent confound significantly limits investigation of part-list cuing mechanisms. Bäuml and Aslan (2004) addressed this confound by separating cuing (with the instruction that the items could be used as cues on a later recall test) from a category-plus-first-letter cued recall task. Likewise, we removed the inherent confound in part-list cuing by temporally separating cues (with the instruction to use them to mentally recall remaining items) from a recognition task and then administering a final free recall task.

An overwhelming majority of part-list cuing experiments have employed recall as the dependent measure. Those that have used recognition have shown equivocal results: Slamecka (1975) found no effect of part-list cues, whereas Todres and Watkins (1981) demonstrated part-set cuing inhibition. Using a study list composed of exemplars of multiple categories, Todres and Watkins found part-set cuing inhibition with extralist, intracategory cues; intralist cues impaired recognition only if the study list was not blocked by category. ${ }^{1}$ They concluded that an important component for part-set cuing inhibition in recognition tasks is that the cues do not reinstate the study context, the facilitating effects of which are presumed to override part-set cuing inhibition.

Todres and Watkins (1981) acknowledged that they may have found part-list cuing impairment by using a more sensitive measure than did Slamecka (1975). We extended this interpretation by measuring latency to recognize items, thereby providing a more sensitive measure of accessibility, while discouraging context reinstatement in two ways: not having the intralist cues present during test and using a speeded yes/no recognition task.
A similar RT procedure was used by Neely, Schmidt, and Roediger (1983). After studying categorized lists, participants studied either two or six primes (exemplars from studied categories), half of which were extralist. In a subsequent speeded yes/no recognition task, RT to identify intralist targets was longer if the target had been preceded by six primes, rather than by two. This experiment supports the idea that increasing the number of cues may decrease access to the remaining exemplars. We extended this research by (1) using a more typical part-list cuing instruction, (2) using only intralist items, and (3) measuring RT differences against an uncued baseline. The latter is particularly important in comparing our results with those for related phenomena, such as retrieval-induced forgetting.

As has been mentioned, Bäuml and Aslan (2004) highlighted the importance of controlling output order for determining the causes of part-list cuing impairment (see also Peynircioğlu, 1989). In our Experiment 1, output order was controlled by using a yes/no recognition task, thereby allowing a direct comparison with other, related phenomena. To measure the persisting effects of part-list cues, a free recall task was administered after the recognition task. Because we did not control output order in our final task, we acknowledge that any free recall differences across cuing conditions cannot be used to distinguish between effects of retrieval competition and those of inhibition (see Bäuml \& Aslan, 2004). However, it allows a direct comparison with previous research on the persisting effects of cues on free recall.

The general finding for the enduring effects of cues is that there is no difference between cued and uncued conditions in free recall (B. H. Basden, D. R. Basden, Church, \& Beaupre, 1991; D. R. Basden \& B. H. Basden, 1995; D. R. Basden et al., 1977; Roediger, Stellon, \& Tulving, 1977). However, a part-list cuing decrement in cued recall was measured in the absence of cues when output order was controlled for through category-plus-first-letter cues (Bäuml \& Aslan, 2004). Park and Madigan (1993) have also demonstrated lasting impairment of part-list cues by separating reminiscence (i.e., recall of new items) and forgetting from the first uncued/cued recall task to a final free recall task. Our goal in employing a final free recall task was to further investigate the assumption of the necessity of cue presence for part-list cuing impairment.

\section{Predictions}

Signal detection and RT. Because strategy disruption explanations rely on the explicit use of cues as search probes, their nonuse in the present procedure should result in no change in access to noncued items. In the first phase of Experiment 1, intralist "cues" were presented and removed before the speeded recognition task with noncue items and lures. In this procedure, using the "cues" in an explicit search during the recognition task was highly unlikely for at least five reasons: The cues were not present during test, the task was speeded, no reference was made to using the cues during test, no reference was made to remembering the cues, and no item recall was necessary. 
In the delayed free recall task, again, there was no reference to the cues, nor were they present during test. In sum, strategy disruption predicts no part-list cuing impairment in either the speeded recognition task or the delayed free recall task.

In our procedure, the retrieval competition hypothesis (Rundus, 1973) does not predict slowed identification or reduced identification accuracy for studied items after cuing. To review, the retrieval competition hypothesis assumes an increase in strength from cue presentation, the effect of which is enhanced access to the cues, relative to the target items. This hypothesis does not predict that target items become less accessible; they are merely occluded by the strengthened cue items (see M. C. Anderson \& Neely, 1996). So, without making unlikely assumptions, retrieval competition predicts no difference in our recognition task measures of recognition time and accuracy across cuing conditions.

Our procedure allowed measurement of the effect of intralist cues on extralist (intracategory) exemplars. According to the retrieval inhibition hypothesis, cue presentation may encourage covert retrieval of cues, decreasing accessibility to noncued items. In our procedure, this would be manifested by a slower response for recognizing target items (i.e., hits) and a lower hit rate after cuing (vs. no cuing).

This RT prediction is consistent with the results of previous research in speeded exemplar recognition after prior exposure to other intracategory test items (Neely et al., 1983). In related research, Brown (1981) found that the retrieval latency for category exemplar generation increased (and retrieval probability decreased) with the number of exemplar generation trials within a category. With the present procedure, if it is assumed that intralist cues increase accessibility in a way similar to that for retrieval of those exemplars, the retrieval inhibition hypothesis would predict slowed access to noncued target items after cuing and more signal detection misses in recognition accuracy in the cued than in the uncued conditions. Retrieval inhibition also would predict lower false alarm rates, due to the suppression of extralist (intracategory) exemplars (M. C. Anderson, 2003), on the basis of Starns and Hicks's (2004) finding that retrieving an item subset reduced activation of extralist, associatively related items.

Free recall. The absence of detrimental effects of cuing on final free recall tests has been argued to support the strategy disruption hypothesis. Specifically, even though the presentation of a cue may strengthen access to that cue item, "removal of the part-list cues allows participants to return to their original retrieval strategy" (D. R. Basden \& B. H. Basden, 1995, p. 1657). (However, we posit that cues, although absent, might still be used in free recall.) In contrast, both retrieval competition and retrieval inhibition predict enduring impairment from part-list cues. Retrieval competition predicts lasting effects if the cues are still more accessible than the noncues. Retrieval inhibition predicts the same, but through the mechanism of suppression of related items from retrieval of cues. This is supported by the lasting impairment of cues on a cued recall task (Bäuml \& Aslan, 2004) and from the body of research on retrieval-induced forgetting that has demonstrated lasting impairment from part-list retrieval on a temporally separated test phase (e.g., M. C. Anderson et al., 1994; Bäuml \& Kuhbandner, 2003).

\section{EXPERIMENT 1}

The participants first studied a list of category exemplars, completed a short distractor task, and then either studied a subset of the original exemplars or continued the distractor task. A speeded yes/no recognition test of new (extralist) and studied (noncue) exemplars followed. The signal detection outcomes (hit, miss, correct rejection, or false alarm) were collected, along with RTs. Finally, a free recall task of all the originally studied items was administered. Strategy disruption predicts no impairment in any of our measures, retrieval competition predicts impairment in free recall, and retrieval inhibition predicts impairment in RT, recognition accuracy, and free recall.

\section{Method}

\section{Participants}

One hundred forty-four undergraduates participated in partial fulfillment of course requirements. Sixty-two participants were Duke University students, and 82 were California State University, Fresno students.

\section{Design and Materials}

The single independent variable of cues was manipulated within subjects. Before testing, cues were either present or absent within a trial. Fifteen exemplars from each of 18 categories were selected from published category norms (Battig \& Montague, 1969). To avoid list effects, exemplars were rotated so that each occurred equally often as a lure, cue, or studied/tested item across participants. To avoid category frequency effects, lists of lure, cue, and study/test items were created by selecting every third exemplar after each category had been sorted by frequency. Items were then randomized within each list.

An IBM-compatible 486 PC was used to present all the stimuli, record RTs, and record recognition accuracy at Duke University, using Micro Experimental Laboratory software (Schneider, 1988). An IBM-compatible Pentium PC was used at California State University, Fresno.

\section{Procedure}

After two practice trials (uncued followed by a cued trial), each participant was given nine cued and nine uncued randomly ordered trials. For each trial, the participant read aloud a category label and 10 exemplars, each presented individually for $1 \mathrm{sec}$ with a 1 -sec interstimulus interval (ISI). A distractor task of either 30 or $20 \mathrm{sec}$ (in an uncued or a cued condition, respectively), consisting of verbal answers to simple math problems (presented for 1,500 msec with a $500 \mathrm{msec}$ ISI), was then given. The cued participants were then shown a pseudorandom subset of five intralist items (two to three from each half of the study list) for $7 \mathrm{sec}$ and were told to read them aloud and use them to mentally recall the remaining items. (Typically, cues are used for explicitly recalling the remaining list items.) This instruction, if anything, is weighted against finding a part-list decrement: Recall of noncues during cuing should increase their access, relative to an uncued condition.

After the distractor or distractor-plus-cues, the participants were given a speeded yes/no recognition task of 5 intralist (noncue) and 5 extralist items, randomly ordered. The participants were instructed to press a key labeled "N" (the " $\mathrm{z}$ " key) if they had not studied the item 
and the key labeled "Y" (the "/" key) if they had studied the item. Responses were to be given as quickly and as accurately as possible. If an error was made, the computer would emit a beep. Following the 10item recognition task, the participants were instructed to write down all the originally studied words on a provided packet. After written free recall, the participants proceeded with the next trial. The participants were tested individually and were audiotaped to ensure that category label, study words, math solutions, and cues were said aloud.

\section{Results and Discussion}

Three types of data were analyzed: RT, signal detection, and free recall. An alpha level of .05 was used for all analyses, unless otherwise indicated. All hypothesis tests were two-tailed.

\section{Reaction Time}

All RTs above 4,000 msec were trimmed from the analyses (approximately $0.2 \%$ of the data). Means (in milliseconds) and standard deviations for all the conditions are shown in Table 1.

Correct responses. Analyses revealed a main effect of list source, so that hits were recognized more quickly than correct rejections ( $M \mathrm{~s}=746$ and $826 \mathrm{msec}$, respectively) $\left[F(1,143)=239.77, M S_{\mathrm{e}}=3,881.23, p<.001 ; d=.55\right]$. A marginal main effect of cuing was revealed, so that words were recognized more quickly in the uncued condition $(M=782 \mathrm{msec})$ than in the cued $(M=791 \mathrm{msec})$ $\left[F(1,143)=3.00, M S_{\mathrm{e}}=3,999.37, p=.085 ; d=.06\right]$. A $2 \times 2$ within-subjects ANOVA revealed no interaction between list source (hits/correct rejections) and cuing condition (cued/uncued) $\left[F(1,143)=2.58, M S_{\mathrm{e}}=1,430.11\right]$.

A follow-up paired samples $t$ test for hits demonstrated that recognition was faster in the uncued condition $(M=739 \mathrm{msec}, S D=144)$ than in the cued $(M=$ $753 \mathrm{msec}, S D=146)[t(143)=2.43 ; d=.10]$. A paired samples $t$ test for correct rejections revealed no RT difference across uncued and cued conditions $(M \mathrm{~s}=824$ and $828 \mathrm{msec}, S D \mathrm{~s}=145$ and 151 , respectively) $[t(143)=$ $0.63]$. Together, these analyses suggest that processing cues before the yes/no speeded recognition task lengthened RT to the remaining, originally studied items (relative to an uncued baseline) but did not slow responses to extralist (intracategory) exemplars.

This part-list cuing decrement shows four points of interest. First, the impairment can be measured through

Table 1

Mean Reaction Times (in Milliseconds) for Cued and Uncued Trials as a Function of Study and Response Conditions

\begin{tabular}{|c|c|c|c|c|c|}
\hline \multirow{3}{*}{$\begin{array}{c}\text { Study } \\
\text { Condition }\end{array}$} & \multirow[b]{3}{*}{ Trials } & \multicolumn{4}{|c|}{ Response Condition } \\
\hline & & \multicolumn{2}{|c|}{ Studied } & \multicolumn{2}{|c|}{ Not Studied } \\
\hline & & $M$ & $S D$ & $M$ & $S D$ \\
\hline \multirow[t]{2}{*}{ Studied } & Uncued & 739 & 144 & $898^{a}$ & 272 \\
\hline & Cued & 753 & 146 & $956^{\mathrm{a}}$ & 338 \\
\hline Mean difference & & $+14^{*}$ & & $+58^{\dagger}$ & \\
\hline \multirow[t]{2}{*}{ Not studied } & Uncued & $956^{\mathrm{a}}$ & 322 & 824 & 145 \\
\hline & Cued & $947^{\mathrm{a}}$ & 239 & 828 & 151 \\
\hline Mean difference & & -9 & & +4 & \\
\hline
\end{tabular}

an RT procedure. Second, it can be demonstrated in a recognition task outside of the limitations described by Todres and Watkins (1981). Third, the presence of cues is not necessary for part-list cuing impairment. Fourth, our finding of a part-list cuing decrement in the absence of any retrieval strategy while controlling order of item presentation in the speeded recognition task provides support for the retrieval inhibition interpretation of part-list cuing effects. These issues are discussed in the General Discussion section.

Incorrect responses. Sixteen participants did not commit any false alarms in one or both of the two cuing conditions and were eliminated from false alarm analyses. A paired samples $t$ test for false alarms revealed a marginally significant RT difference between cuing conditions, so that recognition was faster in the uncued condition $(M=$ $898 \mathrm{msec}, S D=272)$ than in the cued $(M=956 \mathrm{msec}$, $S D=338)[t(127)=1.92, p=.057 ; d=.19]$.

Sixteen participants did not commit any misses (5 of whom also did not commit any false alarms) in one or both of the two cuing conditions and were eliminated from miss analyses. A paired samples $t$ test on misses revealed no RT differences between uncued and cued conditions $(M \mathrm{~s}=956$ and $947 \mathrm{msec}, S D \mathrm{~s}=322$ and 239, respectively) $[t(127)=0.72]$.

\section{Signal Detection}

See Table 2 for a summary of accuracy, discriminability, and response bias measures. Accuracy rates are given in proportions of responses (out of 45 responses in each of the four outcomes: hits/false alarms $\times$ uncued/cued).

Recognition accuracy. In the speeded yes/no recognition task, the participants were more accurate at identifying studied targets (i.e., hit rate) in the uncued condition $(M=.904, S D=.06)$ than in the cued condition $(M=$ $.880, S D=.08)[t(143)=3.95 ; d=.28]$. (This also indicates that more misses, the complement to hits, occurred in the cuing condition.) False alarm rates did not differ across cuing conditions (uncued, $M=.119, S D=.09$; cued, $M=.121, S D=.09)[t(143)=0.31]$.

The finding of higher hit rates in the uncued condition is most consistent with the retrieval inhibition hypothesis of part-list cuing. As with the predictions for RT, presumed covert retrieval of cues causes inhibition of other intracategory exemplars. However, equal false alarm rates across cuing conditions seem inconsistent with part-list cuing predictions based on retrieval inhibition. This may reflect a speed-accuracy trade-off, particularly given the longer RT for false alarms (see Table 1).

One potential difficulty with interpreting the differences in RT hits is that there was a significant difference in hit rate across cuing conditions. Thus, the difference in RT might have been driven by the fact that different items are being compared. Two follow-up analyses suggested that this was not the case. First, there was no correlation between the difference in hit rate and the difference in RT hits $[r(143)=-.074]$. That is, the effect of part-list cuing impairment on accurate responses to studied items did not correlate with the impairment to RT for identifying stud- 
Table 2

Recognition Accuracy, Discriminability $\left(d^{\prime}\right)$, and $\operatorname{Response} \operatorname{Bias}(\beta)$ Across Cuing Conditions

\begin{tabular}{|c|c|c|c|c|c|c|c|c|}
\hline \multirow[b]{2}{*}{ Cuing Condition } & \multicolumn{2}{|c|}{$\begin{array}{c}\text { Proportion of } \\
\text { Hits }\end{array}$} & \multicolumn{2}{|c|}{$\begin{array}{l}\text { Proportion of } \\
\text { False Alarms }\end{array}$} & \multicolumn{2}{|c|}{$d^{\prime}$} & \multicolumn{2}{|c|}{$\beta$} \\
\hline & $M$ & $S D$ & $M$ & $S D$ & $M$ & $S D$ & $M$ & $S D$ \\
\hline Uncued & .904 & .06 & .119 & .09 & 2.70 & 0.72 & 1.28 & 1.44 \\
\hline Cued & .880 & .08 & .121 & .09 & 2.58 & 0.78 & 1.41 & 1.33 \\
\hline Difference & $\begin{array}{c}.024^{* * *} \\
(d=.28)\end{array}$ & & .002 & & $\begin{array}{c}0.12^{*} \\
(d=.17)\end{array}$ & & 0.13 & \\
\hline
\end{tabular}

${ }^{*} p=.05 . \quad{ }^{* * *} p=.001$.

ied exemplars as old. Second, we conducted a follow-up analysis in which cued and uncued weighted mean RTs for all the studied items (i.e., hits and misses) were calculated for each participant. A paired samples $t$ test showed a significant difference between these measures, so that responses in the uncued condition $(M=754 \mathrm{msec}, S D=$ $141)$ were slower than those in the cued condition $(M=$ $774 \mathrm{msec}, S D=152)[t(143)=2.24 ; d=.13]$. This analysis shows that even when all the studied items were considered, there was still a difference in RT across cuing conditions, thereby suggesting that the part-list cuing impairment on RT was not driven by differential recognition accuracy rates across cuing conditions.

Discriminability and response bias. Although the RT and hit rate comparisons suggest part-list cuing impairment, it may be the case that processing cues simply creates a response bias and/or changes in sensitivity toward the response items. The discriminability index $d^{\prime}$ is often used to measure sensitivity to a stimulus in a signal detection paradigm (Macmillan, 1993). In the present study, the "signal" refers to whether the tested word (in the yes/no recognition task) was initially studied in the encoding phase. One explanation for a longer RT after cuing (in comparison with no cuing) is that the presence of cues prior to test reduces discriminability of or sensitivity to the test items. To address this possibility, two $d^{\prime}$ values were calculated for each participant (cued $d^{\prime}$ and uncued $d^{\prime}$; see Macmillan, 1993). ${ }^{2}$ A paired samples $t$ test revealed higher $d^{\prime}$ values (i.e., greater sensitivity) in the uncued condition $(M=2.70, S D=0.72)$ than in the cued condition $(M=2.58, S D=0.78)[t(143)=2.31$; $d=.17]$. This analysis suggests that the participants were better able to discriminate studied from nonstudied exemplars in the uncued condition. This is consistent with our finding of part-list cuing impairment on RT.

Response bias is the tendency to respond with one response over another (e.g., old over new; Macmillan, 1993). With regard to the present study, an explanation for the longer mean RT after cuing (in comparison with no cuing) is that the presence of cues prior to test created a response bias that differed across cued and uncued conditions. This possibility is consistent with RT models that demonstrate that a change in a response bias may result in a change in RT (e.g., Ratcliff, 1978).

In the present study, a longer mean RT in the cued condition may simply reflect a shift in a response criterion.
An outcome demonstrating a differential response bias across cuing conditions would suggest that cues alter the process by which a response is given, consistent with the strategy disruption interpretation of part-list cuing effects. Alternatively, an outcome demonstrating no response bias as a function of cuing would support a retrieval inhibition interpretation of the phenomenon.

To examine this, we used the response bias index beta ( $\beta$ ). (To avoid the inherent asymmetry of $\beta$, we used the $\log \beta$ measure in all the analyses [see Wickens, 2002].) As has been suggested by Wickens, $\beta$ is preferable over the response bias index $c$ (referring to criterion, also called $\lambda_{\text {center }}$ ) for at least two reasons. First, $c$ is calculated only on the false alarm rate, without accounting for hit rates. Thus, $\beta$ generalizes to a variety of situations that $c$ does not. Second, as was stated by Wickens,

[beta] seems somewhat closer to what is intended by the word "bias." An observer who is biased toward a particular alternative will choose it even when the evidence on which the choice was made is more likely to have occurred were the other alternative true. (p. 31)

Theoretically, predictions are unclear on the direction of a response bias as a function of cuing. Thus, any response bias difference across cuing conditions may provide an alternative explanation of RT differences. To address this issue, two $\beta$ values were calculated for each participant (cued $\beta$ and uncued $\beta$ ). A paired samples $t$ test revealed no difference between mean $\beta$ s across uncued and cued conditions $[M \mathrm{~s}=1.28$ and $1.41, S D \mathrm{~s}=1.44$ and 1.33 , respectively; $t(143)=0.92]$.

As a likelihood ratio measure, a response bias $\beta$ of 1 indicates no bias. Values less than 1 indicate a bias toward responding with yes (i.e., a response that the item had appeared in the original study list), whereas values greater than 1 indicate a bias toward no (i.e., a new, nonstudied item). To assess the existence of bias, one-sample $t$ tests were conducted against the test value 1 . Both uncued and cued $\beta \mathrm{s}$ were significantly greater than $1[t \mathrm{~s}(143)=2.35$ and 3.72, respectively], indicating a bias in both uncued and cued conditions toward extralist, intracategory exemplars (i.e., lures, or new items) on the yes/no recognition task.

\section{Free Recall}

Obvious misspellings and plural word forms were the only accepted deviations from correct exemplar recall. In 
the cued condition, items were scored as correct only if they had originally appeared on the study list and were not presented as cues. Critical items in the uncued condition were yoked to those in the cued condition. That is, critical exemplars in the uncued condition were those that had been presented during both study and the yes/no recognition task, even though the participants attempted to recall all 10 originally studied exemplars. Thus, all the critical to-be-recalled items in this task had been presented twice: during original learning and during the yes/no recognition task. Average cued and uncued recall proportions for each participant were calculated for 45 items ( 5 critical exemplars per trial $\times 9$ trials).

A paired samples $t$ test demonstrated that mean free recall of intralist items in the uncued condition $(M=.77, S D=$ .14) was higher than intralist recall in the cued condition $(M=.69, S D=.15)[t(143)=9.05, p<.001 ; d=.60]$. Here, the basic effect of a part-list cuing decrement was replicated on a free recall task, as would be predicted by the retrieval competition and retrieval inhibition hypotheses.

Intrusions were defined as recalled items that were not originally displayed or presented as cues. An average intrusion score was calculated for both cued and uncued trials for each participant. A paired samples $t$ test showed significantly more intrusions in the uncued condition $(M=.35, S D=.35)$ than in the cued condition $(M=.28, S D=.31)[t(143)=3.51 ; d=.23]$. (Note the low intrusion rates: approximately one every three trials.) One possibility for this result is that when uncued, the participants lowered their response criterion and simply reported more items, resulting in higher critical item recall and intrusions, relative to the cued condition. However, a paired samples $t$ test of all the recalled items across cuing conditions showed fewer total items in the uncued condition $(M=57.85, S D=11.97)$ than in the cued condition $(M=64.59, S D=11.62)[t(143)=10.81 ; d=.57]$.

\section{EXPERIMENT 2}

An important finding in Experiment 1 was part-list cuing impairment on a final free recall task. It is not known, however, whether this effect was caused by the presentation of cues or the subsequent speeded recognition task. It is possible that the re-presentation of the words during the recognition task may have interfered with access to the studied items in the delayed recall task. Experiment 2 eliminated the confounding variable of re-presentation of items by replacing the speeded yes/no word recognition task with a distractor task consisting of speeded math equation verification trials.

\section{Method}

\section{Participants}

Seventy-two California State University, Fresno undergraduates participated in partial fulfillment of course requirements.

\section{Design, Materials, and Procedure}

Experiment 1 was replicated with a single modification: We replaced the category exemplars in the yes/no speeded recognition task with math equations. Five of the 10 equations required yes (i.e., cor- rect) responses (e.g., $8 \times 4=32$ ), and 5 required no responses (e.g., $9 \times 3=21)$. Thus, the timing in Experiment 1 was the same in the present experiment, both requiring 10 speeded yes/no responses.

The participants read a category label plus 10 individually presented exemplars. Following a simple math distractor task, the participants either were cued with a subset of 5 intralist items (with the same instructions as those in Experiment 1) or were given the yes/no speeded recognition math task. For cued trials, the speeded math task was administered after the 7-sec cue presentation. Written free recall of originally studied items followed the last yes/no response to the math equations.

\section{Results and Discussion}

Free recall of studied items was scored in the same manner as in Experiment 1. Mean proportion of recall of intralist items in the uncued condition $(M=.55, S D=$ .14) was higher than intralist recall in the cued condition $(M=.47, S D=.18)[t(71)=4.41, p<.001 ; d=.49]$. Thus, the part-list cuing impairment with free recall found in Experiment 1 was replicated.

Both retrieval competition and retrieval inhibition predict a part-list cuing decrement in final free recall via output interference and suppression, respectively. To investigate output interference in our data, we calculated a proportion of critical item recall across each serial position of output by cuing condition (see Table 3). The data demonstrate output interference: Critical items were more likely to be recalled earlier in the output sequence in the uncued than in the cued condition. This pattern supports retrieval competition, although it must be acknowledged that effects of retrieval inhibition may be masked by the output interference.

Intrusions were defined as recalled items that were extracategory items (i.e., not cues or originally displayed items). As in Experiment 1, there were significantly more intrusions in the uncued condition $(M=.18, S D=.20)$ than in the cued condition $(M=.27, S D=.26)[t(71)=$ $3.27 ; d=.42]$.

\section{GENERAL DISCUSSION}

In Experiment 1, time to recognize study items was longer when a complementary subset of studied intralist items was presented prior to test than when no items were presented, thereby demonstrating a part-list cuing decrement in a yes/no speeded recognition task. This is noteworthy for several reasons. First, Todres and Watkins (1981) argued that intralist part-list cues impair recognition only if the study list is not blocked by category. Our results provide evidence against this conclusion: Significant part-list cuing impairment on recognition was found

Table 3

Proportions of Critical Items Recalled by Output Position Across Cuing Conditions

\begin{tabular}{lcccccccccc}
\hline \multicolumn{10}{c}{ Cuing } & \multicolumn{8}{c}{ Serial Position of Output } \\
\cline { 2 - 11 } Condition & 1 & 2 & 3 & 4 & 5 & 6 & 7 & 8 & 9 & 10 \\
\hline Uncued & .50 & .45 & .49 & .47 & .48 & .44 & .55 & .52 & .54 & .47 \\
Cued & .18 & .21 & .26 & .32 & .44 & .61 & .65 & .63 & .70 & .59 \\
\hline
\end{tabular}


with intralist intracategory cues when each study list was composed of a single category. Because we did not employ extralist cues, it is not possible to know whether Todres and Watkins's part-list cuing findings with extralist cues were replicated here.

Also, a part-list cuing decrement was shown in an RT procedure. To our knowledge, there have been no published reports of an RT measure in part-list cuing. This finding reinforces the ubiquity of part-list cuing effects (see Nickerson, 1984), while introducing a unique procedure to further explore the phenomenon.

The results also challenge the assertion that part-list cues must be present during test for the cues to impair memory (see D. R. Basden \& B. H. Basden, 1995). Consistent with Bäuml and Aslan's (2004) results, part-list cues impaired access to noncues even though they were not present during testing. In Experiment 1, the cues were processed and removed before test but still impaired recognition speed and accuracy (i.e., fewer hits and more misses after cuing). Moreover, these effects were revealed in the absence of cues in the free recall task that followed the recognition task. Experiment 2 replicated the finding of a part-list cuing decrement in free recall, while removing the confounding factor of the preceding exemplar recognition task in Experiment 1. In both experiments, fewer target items were recalled when the participants had been cued than when no cues had been provided. This result supports evidence of lasting part-list cuing effects in a free recall task (Park \& Madigan, 1993). Together, these findings suggest that the presence of the cues at the time of test is not necessary for measurable part-list cuing impairment.

Consistent with research on retrieval-induced forgetting (M. C. Anderson et al., 1994), our findings demonstrated that cues impair access to related information without being used in an explicit search for target items. In retrieval-induced forgetting, fewer nonpracticed exemplars from practiced categories are recalled than exemplars from unpracticed categories. Both experiments demonstrated a similar pattern: Noncue intralist targets from cued categories were less accessible than intralist targets from uncued categories. In addition, our results parallel the finding of retrieval-induced forgetting in recognition (M. C. Anderson, de Kok, \& Childs, 1997; Hicks $\&$ Starns, 2004).

Our recognition data are most consistent with the recent interpretation of retrieval inhibition (Bäuml \& Aslan, 2004). We hypothesize that covert retrieval of cues inhibited access to related items through suppression, as shown in both accuracy and RT measures. Both strategy disruption and retrieval competition have difficulty explaining the slowed response in a speeded recognition task after cuing.

The retrieval inhibition hypothesis predicts suppression of both intralist and extralist category exemplars from cuing (see M. C. Anderson, 2003). RT and recognition were used to measure intralist (in hits/misses) and extralist (in false alarms/correct rejections) exemplar access. Support for retrieval inhibition predictions on intralist ex- emplars was found in a slowed response to studied items (i.e., hits) and lower recognition accuracy (i.e., fewer hits and more misses) after cuing. (Equal RT across cuing for misses is not predicted but can be accommodated by assuming a speed-accuracy trade-off, particularly in light of the high miss RTs, relative to hits.) Similarly, support for extralist exemplar inhibition was found in slowed responses on false alarms after cuing. However, RTs for correctly rejecting items and recognition accuracy did not differ across cuing conditions. This may reflect a speedaccuracy trade-off, but it also may highlight a subtlety of the phenomenon, particularly in light of the equivocal findings of the part-list effects of extralist cues (e.g., inhibition was found by Watkins, 1975, but none by D. R. Basden et al., 1977). ${ }^{3}$

We also demonstrated lasting detrimental effects of partlist cues on free recall, as is predicted by output interference from retrieval competition (but this may also reflect the influence of retrieval inhibition). Thus, it appears that our part-list cuing effects in recognition and free recall were driven primarily by mechanisms of suppression and interference, respectively. This highlights the complexity of the phenomenon and suggests that various hypotheses of the part-list cuing effects may be valid across various task types.

\section{Reconciling With List Strength Effects}

The retrieval competition explanation of part-list cuing seems consistent with the results in the literature on list strength effects, in which the strengthening of certain items (typically, by increasing study time or presentations) presumably has impaired memory for the remaining items on a list (Ratcliff, Clark, \& Shiffrin, 1990). Ratcliff et al. showed strong evidence for list strength effects in free recall, reasonable evidence in cued recall, but none (or very little) in recognition, seemingly consistent with a retrieval competition interpretation (Roediger, 1978; Rundus, 1973). However, Bäuml (1997) questioned whether strengthening impairs access to other items or whether the effects are due to output bias. As is predicted by retrieval inhibition through a recall-specific mechanism (M. C. Anderson et al., 2000; see M. C. Anderson et al., 1994), list strength effects disappeared when output order was controlled (Bäuml, 1997), thereby demonstrating that list strength effects are likely due to suppression.

Our Experiment 1 mimicked two of the conditions in Ratcliff et al.'s (1990) experiments on list strength effects: Exemplars studied only once (i.e., the uncued condition) could be considered weak items, whereas the cued condition produced mixed lists, in which the re-presented cues were strong relative to their weak noncued category subset. In our recognition task RTs (and free recall), we found that weak items in mixed lists were less accessible than weak items in pure lists, exactly replicating Ratcliff et al. However, strength-dependent competition cannot accommodate this result, since (1) list strength effects disappear with controlled output order (Bäuml, 1997) and (2) we controlled item test order via our speeded recognition task. The most parsimonious explanation, then, is that cues were 
covertly recalled (on the basis of our instruction to use them to recall the remaining items), thereby suppressing noncue item through retrieval inhibition. This directly supports Bäuml and Aslan's (2004) instructed retrieval inhibition hypothesis (see also Ciranni \& Shimamura, 1999), is consistent with retrieval-induced forgetting on recognition (Hicks \& Starns, 2004), and explains why we found differences in recognition, whereas Ratcliff et al. did not.

\section{Conclusions}

The goal of these experiments was to test part-list cuing effects in speeded recognition and free recall. Our speeded recognition results support an instructed retrieval inhibition explanation (Bäuml \& Aslan, 2004), whereas our free recall data support a retrieval competition explanation (Kimball \& Bjork, 2002; Rundus, 1973). The unique contributions of this research fall into two categories: methodology and findings. First, this research introduced a new method of investigating part-list cuing through a speeded yes/no recognition task. Second, we found three unique ways of showing part-list cuing decrements: in $\mathrm{RT}$, in a recognition task with intralist cues, and in a free recall task. Together, these contributions suggest a powerful method for exploring part-list cuing that allows direct comparisons with other memory phenomena.

\section{REFERENCES}

Anderson, J. R., \& Bower, G. H. (1973). Human associative memory. Washington, DC: Winston.

Anderson, M. C. (2003). Rethinking interference theory: Executive control and the mechanisms of forgetting. Journal of Memory \& Language, 49, 415-445.

Anderson, M. C., BJork, E. L., \& BJork, R. A. (2000). Retrievalinduced forgetting: Evidence for a recall-specific mechanism. Psychonomic Bulletin \& Review, 7, 522-530.

Anderson, M. C., Bjork, R. A., \& Bjork, E. L. (1994). Remembering can cause forgetting: Explorations in the retrieval dynamics of long-term memory. Journal of Experimental Psychology: Learning, Memory, \& Cognition, 20, 1063-1087.

Anderson, M. C., DE KoK, D., \& CHILds, C. (1997, November). Retrievalinduced forgetting on a test of recognition memory. Poster presented at the 38th Annual Meeting of the Psychonomic Society, Philadelphia.

Anderson, M. C., \& NeEly, J. H. (1996). Interference and inhibition in memory retrieval. In E. L. Bjork \& R. A. Bjork (Eds.), Memory (pp. 237-313). San Diego: Academic Press.

Basden, B. H., Basden, D. R., Church, B. A., \& Beaupre, P. (1991). Setting boundary conditions on the part-set cuing effect. Bulletin of the Psychonomic Society, 29, 213-216.

BASDEN, D. R., \& BASDEN, B. H. (1995). Some tests of the strategy disruption interpretation of part-list cuing inhibition. Journal of Experimental Psychology: Learning, Memory, \& Cognition, 21, 1656-1669.

Basden, D. R., Basden, B. H., \& Galloway, B. C. (1977). Inhibition with part-list cuing. Journal of Experimental Psychology: Human Learning \& Memory, 3, 100-108.

Battig, W. F., \& Montague, W. E. (1969). Category norms for verbal items in 56 categories: A replication and extension of the Connecticut category norms. Journal of Experimental Psychology, 80(3, Pt. 2), $1-46$.

B ̈̈UML, K.-H. (1997). The list-strength effect: Strength-dependent competition or suppression? Psychonomic Bulletin \& Review, 4, 260-264.

B ̈̈UML, K.-H. (2002). Semantic generation can cause episodic forgetting. Psychological Science, 13, 356-360.

B ÄUML, K.-H., \& Aslan, A. (2004). Part-list cuing as instructed retrieval inhibition. Memory \& Cognition, 32, 610-617.

B̈̈UmL, K.-H., \& KuHBANDnER, C. (2003). Retrieval-induced forget- ting and part-list cuing in associatively structured lists. Memory \& Cognition, 31, 1188-1197.

Brier-BAuder, G., \& Knoedler, A. J. (1999, May). Reinvestigating the effects of part-set cuing on recognition memory. Poster presented at the 79th Annual Meeting of the Western Psychological Association, Irvine, CA.

Brown, A. S. (1981). Inhibition in cued retrieval. Journal of Experimental Psychology: Human Learning \& Memory, 7, 204-215.

Ciranni, M. A., \& Shimamura, A. P. (1999). Retrieval-induced forgetting in episodic memory. Journal of Experimental Psychology: Learning, Memory, \& Cognition, 25, 1403-1414.

HicKs, J. L., \& StARNS, J. J. (2004). Retrieval-induced forgetting occurs in tests of item recognition. Psychonomic Bulletin \& Review, 11, 125-130.

Kimball, D. R., \& BJork, R. A. (2002). Influences of intentional and unintentional forgetting on false memories. Journal of Experimental Psychology: General, 131, 116-130.

Macmillan, N. A. (1993). Signal detection theory as a data analysis method and psychological decision model. In G. Keren \& C. Lewis (Eds.), A handbookfor data analysis in the behavioral sciences: Methodological issues (pp. 21-57). Hillsdale, NJ: Erlbaum.

Macmillan, N. A., \& Creelman, C. D. (1991). Detection theory: A user's guide. New York: Cambridge University Press.

Mueller, C. W., \& Watkins, M. J. (1977). Inhibition from part-set cuing: A cue-overload interpretation. Journal of Verbal Learning \& Verbal Behavior, 16, 699-709.

Neely, J. H., Schmidt, S. R., \& Roediger, H. L., III (1983). Inhibition from related primes in recognition memory. Journal of Experimental Psychology: Learning, Memory, \& Cognition, 9, 196-211.

Nickerson, R. S. (1984). Retrieval inhibition from part-set cuing: A persisting enigma in memory research. Memory \& Cognition, 12, 531-552.

Park, H., \& Madigan, S. (1993). Negative effects of part-set cues: Are they reversible? Bulletin of the Psychonomic Society, 31, 311-313.

PeYNiRCioǦLU, Z. F. (1989). Part-set cuing effect with word-fragment cuing: Evidence against the strategy disruption and increased-listlength explanations. Journal of Experimental Psychology: Learning, Memory, \& Cognition, 15, 147-152.

RaAiJmakers, J. G. W., \& Phaf, R. H. (1999). Part-list cuing revisited: Testing the sampling-bias hypothesis. In C. Izawa (Ed.), On human memory: Evolution, progress, and reflections on the 30th anniversary of the Atkinson-Shiffrin model (pp. 87-104). Mahwah, NJ: Erlbaum.

RAAIJMAKERS, J. G. W., \& ShIFFrIN, R. M. (1981). Search of associative memory. Psychological Review, 88, 93-134.

RAtCliff, R. (1978). A theory of memory retrieval. Psychological Review, 85, 59-108.

Ratcliff, R., Clark, S. E., \& Shiffrin, R. M. (1990). List-strength effect: I. Data and discussion. Journal of Experimental Psychology: Learning, Memory, \& Cognition, 16, 163-178.

Reysen, M. B., \& NaIrne, J. S. (2002). Part-set cuing of false memories. Psychonomic Bulletin \& Review, 9, 389-393.

Roediger, H. L., III (1974). Inhibiting effects of recall. Memory \& Cognition, 2, 261-269.

Roediger, H. L., III (1978). Recall as a self-limiting process. Memory \& Cognition, 6, 54-63.

Roediger, H. L., III, \& NeEly, J. H. (1982). Retrieval blocks in episodic and semantic memory. Canadian Journal of Psychology, 36, 213-242.

Roediger, H. L., III, Stellon, C. C., \& Tulving, E. (1977). Inhibition from part-list cues and rate of recall. Journal of Experimental Psychology: Human Learning \& Memory, 3, 174-188.

RuNDUs, D. (1973). Negative effects of using list items as recall cues. Journal of Verbal Learning \& Verbal Behavior, 12, 43-50.

SCHNEIDER, W. (1988). Micro Experimental Laboratory: An integrated system for IBM PC compatibles. Behavior Research Methods, Instruments, \& Computers, 20, 206-217.

SlamecKA, N. J. (1968). An examination of trace storage in free recall. Journal of Experimental Psychology, 76, 504-513.

SLAMECKA, N. J. (1969). Testing for associative storage in multitrial free recall. Journal of Experimental Psychology, 81, 557-560.

SLAMECKA, N. J. (1975). Intralist cueing of recognition. Journal of Verbal Learning \& Verbal Behavior, 14, 630-637. 
Smith, A. D. (1971). Output interference and organized recall from long-term memory. Journal of Verbal Learning \& Verbal Behavior, 10, 400-408.

Starns, J. J., \& Hicks, J. L. (2004). Episodic generation can cause semantic forgetting: Retrieval-induced forgetting of false memories. Memory \& Cognition, 32, 602-609.

Todres, A. K., \& WatKins, M. J. (1981). A part-set cuing effect in recognition memory. Journal of Experimental Psychology: Human Learning \& Memory, 7, 91-99.

WATKINs, M. J. (1975). Inhibition in recall with extralist "cues." Journal of Verbal Learning \& Verbal Behavior, 14, 294-303.

WiCKENS, T. D. (2002). Elementary signal detection theory. New York: Oxford University Press.

\section{NOTES}

1. However, evidence of part-list cuing impairment in a forced choice recognition task has been found using intralist cues, with the study list blocked by category (Brier-Bauder \& Knoedler, 1999).
2. Sixteen participants did not commit any misses, and 16 did not commit any false alarms. Thus, their $d^{\prime}$ 's could not be calculated. There has been a variety of opinions on how to approach this issue. The consensus appears to point to the method described by Macmillan and Creelman (1991): "To avoid infinite values, it is common to convert proportions of 0 and 1 to $1 /(2 N)$ and $1-1 /(2 N)$, respectively" (p. 10). Out of the 45 possible responses for a participant in each condition, proportions were adjusted by subtracting .01 from $p$ (hit) or adding .01 to $p$ (false alarm), resulting in $z$ scores of 2.33 and -2.33 , respectively.

3. There is an important difference between the previous research, in which extralist exemplars have been used in a part-list cuing procedure, and the present study. All previous research has investigated the effects of extralist cues on intralist exemplars. In contrast, our procedure investigated the effects of intralist cues on extralist exemplars.

(Manuscript received September 10, 2004; revision accepted for publication April 6, 2005.) 